\title{
Cardiac lipoma arising from left ventricular papillary muscle: Resect or not?
}

Young Sam Kim, MD, ${ }^{a}$ Kyung Hee Lee, MD, PhD, ${ }^{b}$ Suk Jin Choi, MD, PhD, ${ }^{c}$ and Wan Ki Baek, MD, PhD ${ }^{a}$

\footnotetext{
From the Departments of ${ }^{\mathrm{a}}$ Thoracic and Cardiovascular Surgery, ${ }^{\mathrm{b}}$ Diagnostic Radiology, and ${ }^{\mathrm{c}}$ Pathology, Inha University Hospital, Incheon, South Korea.

Disclosures: Authors have nothing to disclose with regard to commercial support.

Received for publication Oct 16, 2017; revisions received Jan 8, 2018; accepted for publication Jan 16, 2018; available ahead of print Feb 28, 2018.

Address for reprints: Wan Ki Baek, MD, PhD, Department of Thoracic and Cardiovascular Surgery, Inha University Hospital, 27, Inhang-ro, Jung-gu, Incheon 22332, South Korea (E-mail: wkbaek@inha.ac.kr).

J Thorac Cardiovasc Surg 2018;156:244-6

$0022-5223 / \$ 36.00$

Copyright (c) 2018 by The American Association for Thoracic Surgery

https://doi.org/10.1016/j.jtcvs.2018.01.040
}

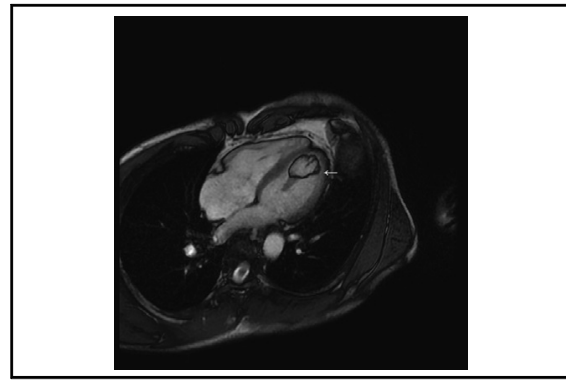

A well-circumscribed mass at the base of posterior papillary muscle of the left ventricle.

\section{Central Message}

We report a rare case of cardiac lipoma arising from posterior papillary muscle of the left ventricle. The appropriateness of surgical resection is addressed.

See Editorial Commentary page 247.
A 42-year-old Asian man with an intracardiac mass found incidentally during a health check-up was referred for surgery. He had neither symptoms nor preexisting conditions. Cardiac imaging demonstrated a $3 \times 3-\mathrm{cm}$ well-circumscribed mass arising from posteromedial papillary muscle of the left ventricle, showing a typical feature of lipoma (Figure 1).

Operation was carried out through a median sternotomy with standard hypothermic cardiopulmonary bypass. The left ventricle was explored through a left atriotomy. A yellowish, walnut-sized mass arising from the base of posteromedial papillary muscle and tightly adherent to the ventricular septum toward the apex was excised en bloc with papillary muscle and adherent septal myocardium (Figure 2, $A$ and $B$, and Video 1). The mitral valve was replaced with a mechanical prosthesis. Although we
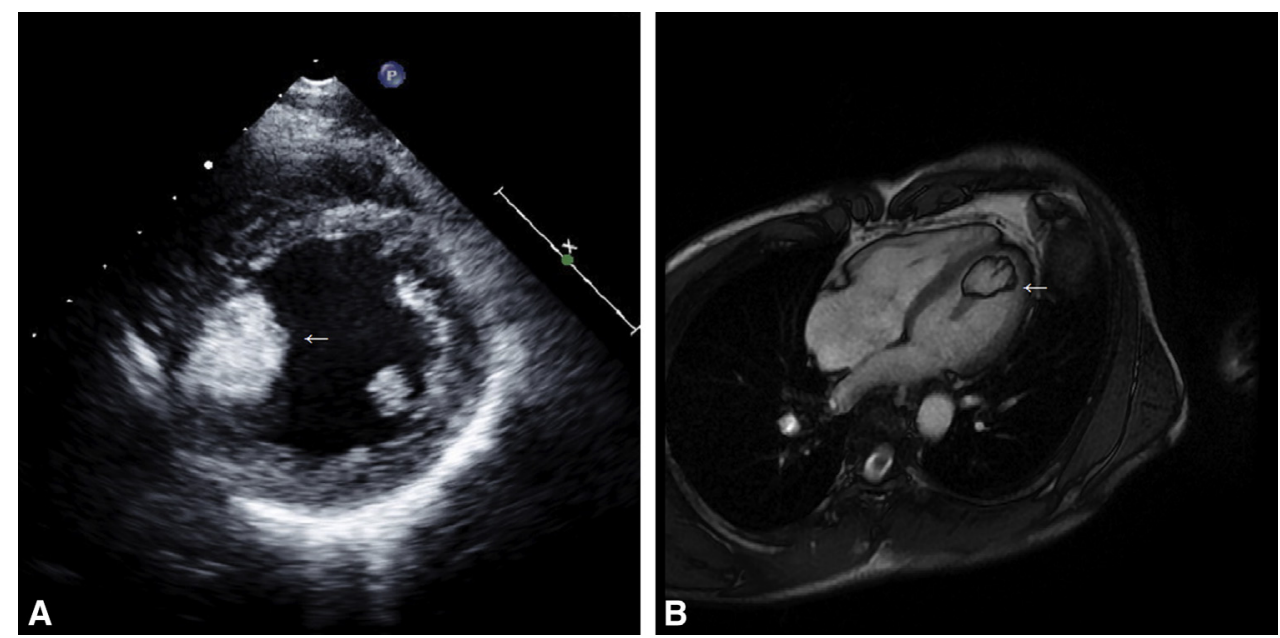

FIGURE 1. Echocardiography (A) and magnetic resonance imaging (B) demonstrating a well-circumscribed, homogenous round mass (arrows) arising from posterior papillary muscle of the left ventricle. The mass shows a typical feature of lipoma, well-circumscribed homogenous density with fat signal intensity by T1-weighted image. 

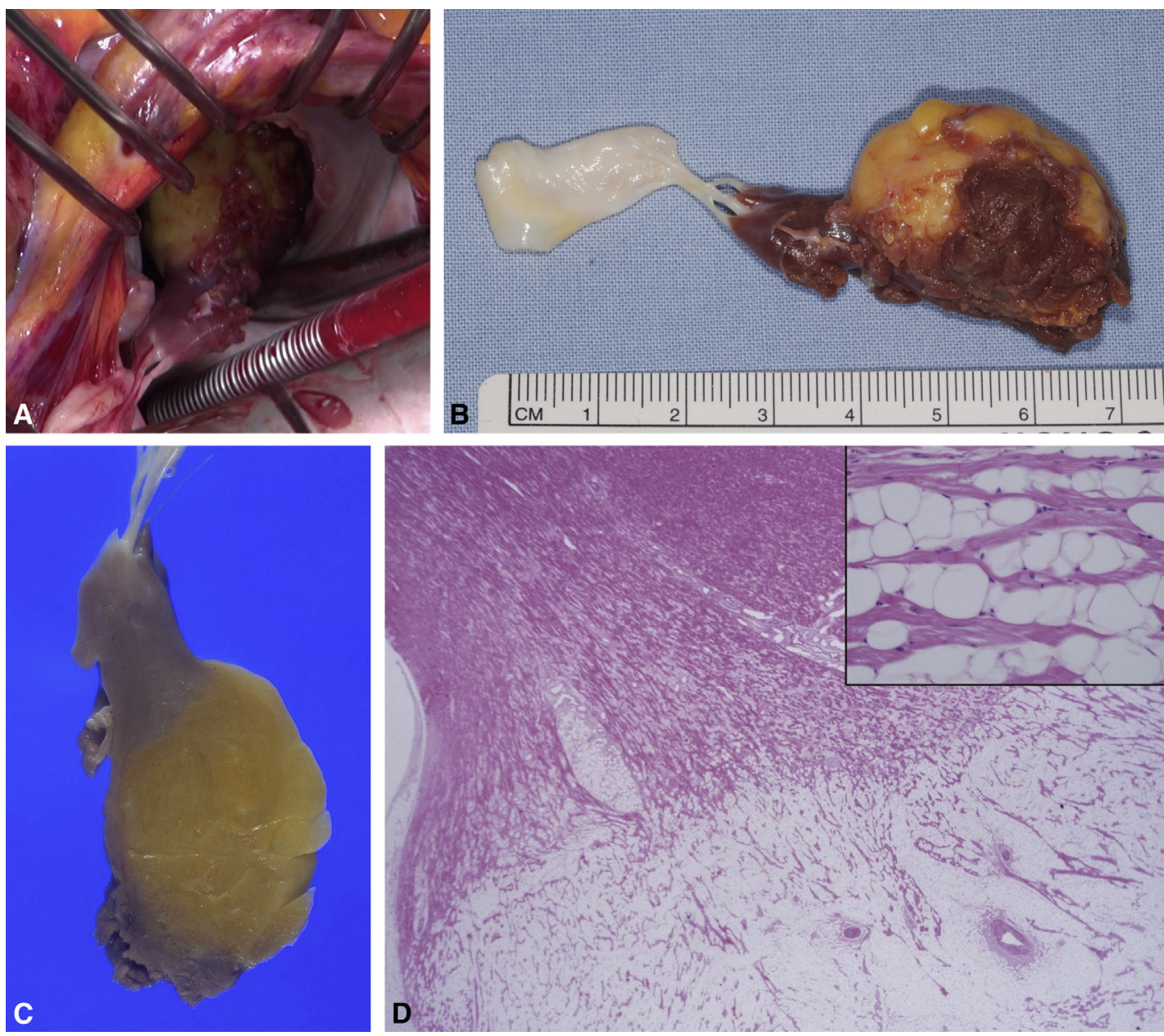

FIGURE 2. Operative view and histopathologic findings. A, The mass is seen from the left atrial side after the removal of mitral valve leaflets. B, In the photograph of the resected mass, note the myocardial tissue resected together with the adipose mass along the lower anterior aspect corresponding to the interventricular septum. C, Cross section of the gross specimen shows gradual replacement of the papillary myocardium by adipose tissue without definite encapsulation. D, Microscopically, the papillary muscle is diffusely infiltrated by mature adipocytes without nuclear atypia (hematoxylin and eosin, original magnification $\times 10$; inset in panel $\mathrm{D}$, hematoxylin and eosin, original magnification $\times 400$ ).

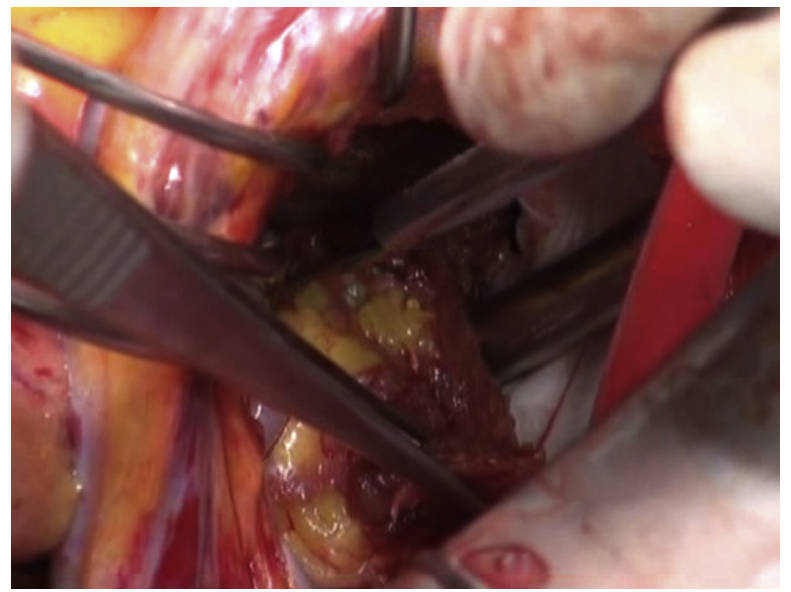

VIDEO 1. Operative procedure. Video available at: https://www.jtcvs.org/ article/S0022-5223(18)30263-0/fulltext. initially considered valve repair, it was not feasible, because the mass was largely obscuring the surgical field (Video 1) and we were reluctant to risk a complex repair procedure such as papillary muscle transfer to the dissected myocardium. Postoperative recovery was uneventful. Histopathologic examination revealed an intramuscular lipoma showing an infiltrative growth into the surrounding myocardium and papillary muscle both grossly and microscopically (Figure 2, $C$ and $D$ ).

Reports of lipomas arising from the papillary muscle of the left ventricle are very rare. We found only 2 cases in our literature search. ${ }^{1,2}$ As described in those cases, surgical indications are less defined when the patient does not have overt symptoms. Considering the benign nature of the tumor, the surgical treatment might be deferred pending follow-up results. On the other hand, 
there are concerns that deferring surgery might further jeopardize the patient because of possible embolic risk. Deferred operation might need to be more extensive, especially when the tumor shows infiltrative nature as in our case. ${ }^{3}$ Given the relatively lower risk of cardiac surgery in the current era, these concerns should be carefully considered.

\section{References}

1. Prestipino F, Cammardella AG, Chello M. Unconventional location for a cardiac lipoma: the anterior papillary muscle. J Cardiol Cases. 2016;14:71-3.

2. Koshy AN, Koshy G, Hardikar AA. Intracardiac lipoma arising from the papillary muscle. J Card Surg. 2011;26:65-6.

3. Fang L, He L, Chen Y, Xie M, Wang J. Infiltrating lipoma of the right ventricle involving the interventricular septum and tricuspid valve. Report of a rare case and literature review. Medicine (Baltimore). 2016;95:e2561. 